\title{
Assessment of occupational accidents in construction sector: A case study in Turkey
}

\author{
G. Kamber Yılmaz , H.B. Başağa \\ Karadeniz Technical University, Department of Civil Engineering, Trabzon, Turkey
}

\begin{abstract}
It is essential to investigate the parameters that have an impact on accident occurrence in light of the precautions that can be taken against possible occupational accidents. Statistics on work-related accidents in Turkey are gathered through Turkish Statistical Institute (TSI) and Social Security Institution (SSI). SSI shares occupational accident data online annually. These data, though, there is not a comprehensive data repository, are not boiled down to province-based and/or work branch specific data. In this study, it is aimed to be able to carry out an in-depth examination of occupational accidents in construction work. For the indepth investigation of occupational accidents in the construction work, causes of accidents are studied using Trabzon SSI Provincial Directorate's occupational accident archive files. From these files, data from 194 occupational accident files have been sorted out related to the construction industry by examining 868 occupational accidents one by one between 2010 and 2011. Data have been classified according to lots of factors, and frequency distribution of factors are examined by performing univariate frequency analysis in SPSS package program. The data obtained from the study is interpreted to put forth the reasons of occupational accidents specific to Trabzon. Besides, it is determined that occupational accidents in Trabzon are compared with Turkey's data, and they show a great resemblance to each other. Finally, some suggestions are put forward towards reducing occupational accidents in this industry.
\end{abstract}

\section{Keywords}

Construction industry; occupational accidents; statistics; frequency analysis

Received: 11 June 2018; Accepted: 29 June 2018

ISSN: 2630-5771 (online) @ 2018 Golden Light Publishing All rights reserved.

\section{Introduction}

While manufacturing from metal articles (without machines), coal mining, construction, weaving industry and manufacture of transportation vehicles are the leading sectors which occupational accidents take place, work accidents in construction industry cause the deaths or the permanent disabilities of the workers [1].

According to American construction industries' 2011 data, 721 people have exposed to severe injury, and 71.600 people have exposed to an occupational accident and occupational disease which results in workday loss [2-4]. Injuries and deaths resulted from work accidents have not only been pain and suffering to the construction worker and his/her family, but it has also resulted with a cost of approximately 27 thousand \$ for each case and 10 billion $\$$ annually [2, 5]. Researches have shown that, in construction and other sectors where accidents are experienced frequently, work-related accidents are not considered important especially by construction workers and few notifications are

\footnotetext{
* Corresponding author

Email: goncakamber@ktu.edu.tr
} 
made [6-11]. Again, enough information about work accidents and occupational diseases cannot be reached in many countries of the world; reported ones are only limited to officially registered workers.

According to ILO's (International Labour Organization) 2010-2011 reports, 337 million work accidents take place annually, 2 million 310 thousand people lose their lives because of these accidents, 160 million people are either injured or are exposed to an occupational disease. These accidents' financial damage is estimated to be 1,2 trillion \$ [12].

Work accidents in Turkey are increasing in number every year. Numerical data of work accidents that took place between 2008-2016 [13] are given in Fig. 1 by statistics that are published by SSI (Social Security Institution) annually. Work accidents that are resulted in injury and death are given in Fig. 1a distributed by years and the distribution of incidence and weight rates of the work accidents are given in Fig. 1b.

While there are 72.098 people injured as a result of work accidents in 2008, this number is increased to 284.663 in 2016. Especially, the increase in work accidents after 2012 is highly remarkable. While the most number of fatal accidents took place in 2011 by 1.700 people, the least number of fatal accidents took place in 2012, between the years 2008-2016. In work accidents incidence rating,

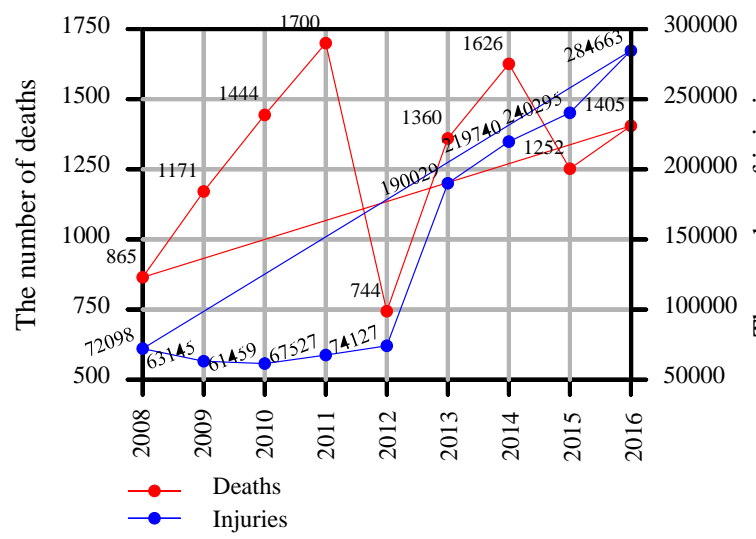

(a) According to the number of injuries and deaths which demonstrates how many insured people experienced work accidents in a calendar year which equivalent to 1.000 .000 hours, it can be seen that, the ongoing decline until 2012 shows a serious increase after 2012 and reaches 7,9 rates in 2016. According to work accidents weight rate, 721 work days lost in 2011, 395 work days lost in 2012 is experienced due to work accidents and in 1.000 .000 hours, and it has reached 665 days in 2016 increasing more and more after 2012.

There are many studies which examine the work safety and work accidents in the construction industry. Studies on work accidents in Turkey and the world mainly focus on accident causes, accident statistics and accident prevention policies. In this study, several studies which have different perspectives are included. In a study which helps to prevent work accidents in building operation, it is determined that lots of risk factors arise even in a large-scale project and sufficient importance is not given to this subject [14]. It is crucial to perform risk analyses, in preventing accidents and losses successfully. Y1lmaz and Şenol [15] who work to this purpose, have increased the efficiency of traditional risk analysis by integrating Fuzzy Logic and Multi-Criteria Decision-Making methods to the risk analysis process in evaluating the danger and the precautions against dangers.

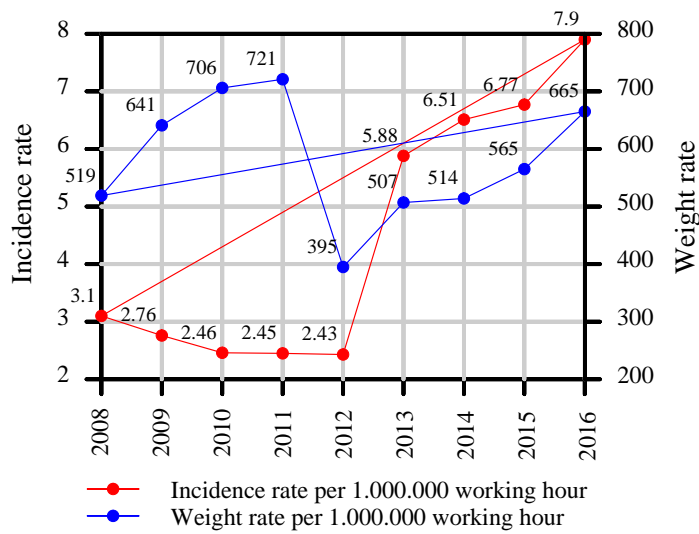

(b) According to incidence rate and weight rate

Fig. 1. Distribution of occupational accidents during 2008-2016 
Y1lmaz and Çelebi [16] have examined three construction sites and their records in 2009 to research the cost of workforce loss as a result of risks that turn into accidents. Workday loss cost is calculated as 19.431,75 \$ in big work accidents and $6.924,25$ \$ in small work accidents. As a result of a survey which is conducted with 800 personnel in order to examine the general health and security situations of Turkish construction industry, it is determined that contractors are not completely performing their legal obligations in paying workers' insurance premium, they are neglecting occupational health and safety training and they are reluctant to provide an occupational physician and PPE (Personal Protective Equipment) [17]. Ceylan, [18] who studies on accident statistics, has examined the statistics of SSI work accidents between the years of 2004-2010. It is detected that $46,4 \%$ of the accidents and $41,1 \%$ of the deaths in Turkey occurred only in mining, metal and construction industries. In order to determine the workers' distribution of terms of reference who are exposed to work accidents, Y1lmaz, [19] has made work accident analyze Retrospective Cohort method depending upon the data that are taken from a construction site in Istanbul between 2012-2013. In the study, it is determined that 18-39 age group and inexperienced workers are more exposed to work accidents; however, qualified workers, foremen, overseers, technicians and administrative personnel experience fewer work accidents and most of the accidents take place within the buildings under construction. In a study which researches the factors of work accidents' severity and the current situation of occupational health and safety in the construction industry, a database which reflects the truth, specific to Turkish construction industry, is formed [20]. On this database possible severity of accidents are tried to be estimated by using advanced analysis methods. One of the studies on the reasons of accidents, Baradan and others [21], have made analyses on the reasons of falling from height accidents which take place in Ege region during construction businesses As a result of the univariate statistical analysis performed with the sorted data from 80 cases which took place between 2009-2010, it is found out that formwork and plaster/paint workers have a larger effect on not using PPE and foremen have a larger impact on the formation of accidents. In addition to studies which covers the whole construction industry, there are also studies in the literature which examines the sub-units. For example, Akboğa and Baradan [22] have examined 49 accident notification form which is obtained from İzmir, Ankara and İstanbul's SSI records to examine and find solutions to transmixer operators who are faced to job security problems. By applying univariate statistical analysis to the acquired data, an accident takes place in every one of the three pump/transmixer cleaning and they conclude that these accidents usually take place by falling from transmixer, contact with chemicals or object crashes. There are studies on work safety in different countries, similar to studies in Turkey. By analyzing 485 work accidents that took place in Poland's five states between 2008-2014, the effects of the employment situation, occupation, age, term of office and the workplace size of the person who experienced the accident is defined [23]. According to the obtained data, it is put forth that, \%37 of the accidents are fatal, $\% 61$ are severe and $\% 2$ are mild accidents. In a study in Hong Kong on construction work safety, technologies that can prevent accidents about crane and can potentially help to minimize them is researched [24]. It is determined that virtual prototype software methodologies and technologies that are developed and applied on the automotive industry, can serve as effective precautions in reducing the accidents and enhancing the safety. In Spain, 567 reports of investigation prepared by OHS (Occupational Health and Safety) technical advisers for work accidents that took place in 2009 in sectors such as construction, production, agriculture and service is examined, in order to analyse how accident examination reports determine the major defects and breakdowns after work accidents [25]. According to the obtained data, it is determined that only the $\% 26,9$ of the reports are prepared in accordance with the quality criteria in literature. In Malaysia's construction industry it is determined that falling of materials 
and crashing of materials accidents are the most common types of work accidents when the statistical data between 2000-2009 and the cases between 1961-2011 is examined [26].

In this study, general details of work accidents that construction industry workers have exposed are put forth within the scope of Trabzon with details that are missing in SSI statistical yearbook. For this purpose, work accidents that took place in the construction industry in Trabzon between 20102011 are examined. Acquired data from the study is scrutinised within the scope of factors that cause the work accidents in the construction industry in Trabzon, parameters about work accidents are interpreted compared to Turkey in general.

\section{Materials and methods}

In order to answer why and how work accidents take place, first of all, work accidents that took place before should be examined in detail. In this study, to determine the work accidents in Trabzon's construction industry and carry out a statistical study about these accidents, Trabzon SSI Provincial Directorate's work accident archive files are scanned. Since the scope of the study includes only 2010 and 2011, 868 archive files about these work accidents which belong to these years are examined one by one. From these files, it is decided to use 194 work accident files that belong to construction industry within the scope of the study. The information obtained is evaluated according to the degree of injury, accident time, the age of employee exposed to the work accident, type of accident, number of insured workers in the workplace, days away from work, type of construction site where the accident happened. Data about factors are registered into SPSS package program by encoding, univariate frequency analysis is performed in order to obtain descriptive information about factors and the frequency distribution of data is observed. SSI inspector reports included in the files, work accident notification forms, witnesses testimonies,' and hospital reports from the source of the data. Findings on univariate frequency analysis are conveyed with the help of pie diagrams. Finally, the comparison between the accidents that take place in
Trabzon and in Turkish construction industry is made. However, since SSI's annual statistics do not allow to examine on a sectoral basis, Akboğa's [20] study is used for comparing work accidents on a sectoral basis. Akboğa aimed to form a current and verisimilar database on Turkish construction industry in his study. Archive studies are done in İzmir, Ankara, İstanbul Social Security Centers, 2024 accident notification forms, limited to work accidents that take place in the construction industry, between 2010-2012 is examined and analyzed statistically. Considering these three cities possess one-third of the house sales and construction volume in Turkey, it was deemed to be sufficient in reaching the goal of the study.

\section{Results}

Analysis results of the 194 work accident data that took place between January 2010 - December 2011 in the construction industry in Trabzon is explained with figures in this section. Analyses that are conducted with SPSS 18 program, data is interpreted depending on ten different findings including, hour, day, month, degree of injury, days away from work, type of accident, age of employee who experienced work accident, number of insured workers in the workplace and the type of the construction site where the accident happened.

Accidents are classified into 4 groups according to the duration of the medical report that is taken from the hospital as a result of the accident According to these classifications they are considered as; accidents that require reports up to 3 days are mild, accidents that require reports between 3-20 days are moderate, accidents that require reports more than 20 days are severe and finally fatal accidents.

Since mild injury accident notifications are not usually reported to the institutions, work accident that resulted in mild injury cannot be found in archive files as a result of this. For this reason, accidents are considered moderate, severe and fatal. According to this classification, the distribution of work accidents according to their injury degrees are given in Fig. 2. In the distribution of accidents according to their injury degrees, $\% 31$ of the 
accidents are moderate, \%66 are severe, and \%3 are fatal. Most of the accidents are severe. Therefore, $\% 97$ of the accidents have resulted in injuries, and $\% 3$ of them have resulted in fatal accidents.

The time when the accidents take place is one of the important parameters that need to be examined. In work accidents' analysis according to accident's time, evaluations are made considering the day of the accident, time of the accident and the month of the accident. Time of the accident indicates the time when the accident took place. In the study, 24 hours are divided into 5 different periods of time in accordance with working hours:

- Morning : 06:00-12:00

- Noon : : 12:00 - 15:00

- Afternoon : 15:00 - 18:00

- Evening : :18:00 - 20:00

- Night : 20:00 - 06:00

Seven days of the week are considered as the day of the accident in the study. Distribution of work accidents according to days and working hours are given respectively in Fig. 3 and Fig. 4. When work accidents are examined in terms of days, Friday is the leading day with \%17,5. Thursday follows Friday with \%16. Work accidents that take place on Saturday, however, has a considerable rate of $\% 15,5$. Least accident, however, takes place on Sunday with \%7,2.

In the distribution of work accidents according to the work hours, it can be seen that \%43,3 take place in the morning, \%13,4 take place in the noon, $\% 22,7$ take place afternoon, \%17,1 take place in the evening and night shifts. According to this, work accidents are experienced more in mornings which are the starting hours. Afternoon follows this.

In the distribution of work accidents according to months, twelve months of the year are taken into consideration and distribution is shown in Fig. 5.

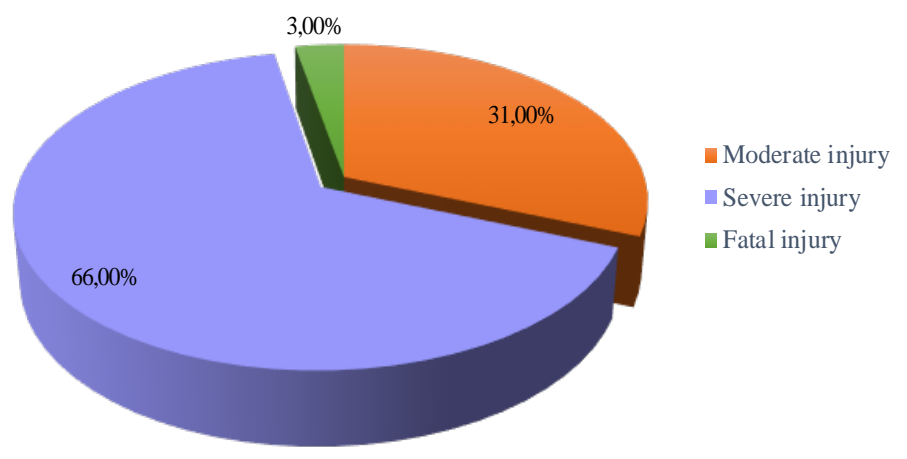

Fig. 2. Percent distribution of occupational accidents by the degree of injury

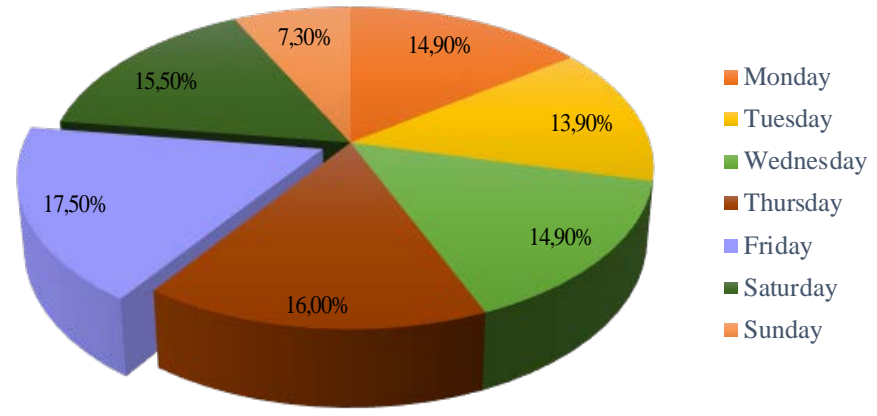

Fig. 3. Percent distribution of occupational accidents by days 


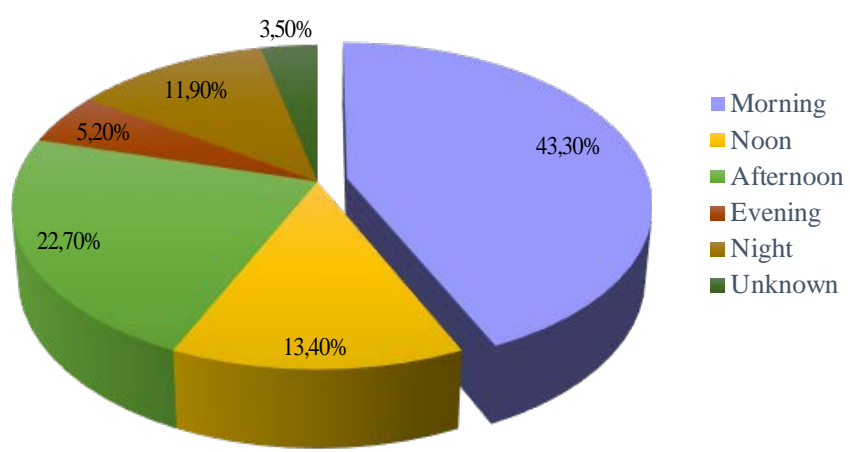

Fig. 4. Percent distribution of occupational accidents by working hours

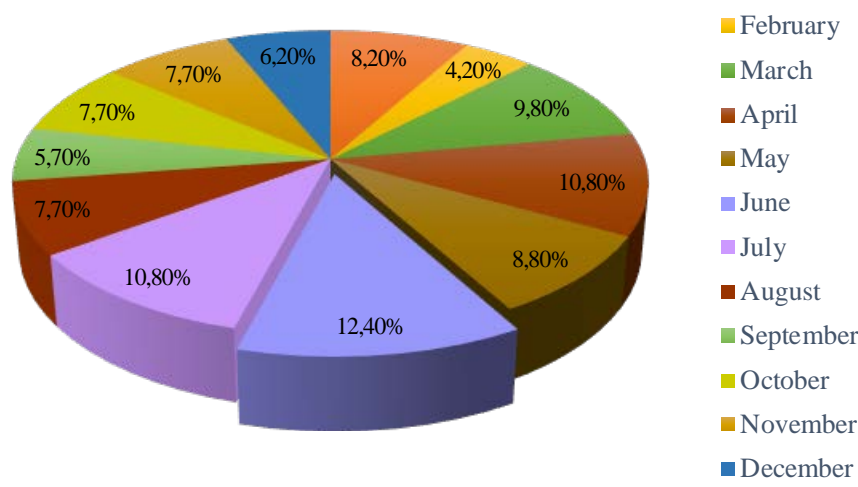

Fig. 5. Percent distribution of occupational accidents by months

According to this, accidents take place most frequent in June with \%12,4. July and April are second in place with \%10,8. Respectively, work accidents take place with a rate of \%9,8 in March, $\% 8,8$ in May and \%8,2 in January. The least work accident takes place in February with $\% 4,2$.

The age of the worker who experienced work accident is another factor in the distribution of work accidents. Age of the workers is classified differently in lots of institutions. In this study, however, SSI's classification system is used. According to this classification, ages are:

$\begin{array}{lll}\cdot 14 & \cdot 15-17 & \cdot 18-24 \\ \cdot 25-29 & \cdot 30-34 & \cdot 35-39 \\ \cdot 40-44 & \cdot 45-49 & \cdot 50-54 \\ \cdot 55-59 & \cdot 60-64 & \cdot 65+\end{array}$

Types of accidents are one of the factors that determine the prevention of work accidents and provides us to understand how accidents occur. In their studies, Müngen et al., have categorized types of accidents which are faced most frequently in construction industry into 14 categories and this categorization type is used in this study. Accident types:

- Falls

- Losing the limb

- Exposure to electricity

- Compressing the limb

- Material fall

- Hand-tapping with a hand tool

- Accidents in the construction machine

- Injury with a sharp tip tool

- Traffic accident on site

- Material bouncing

- Building/structure collapse

- Fire or explosion

- Cave-in (while or after excavation)

- Other types (material striking, object striking, limbs striking machine or materials) 
Fig. 6 and Fig. 7 show the distribution of occupational accidents according to workers' age group and accident types, respectively.

$\% 20,1$ of the workers who are exposed to work accidents are between 25-29. 18-24 age group is second with the rate of \%17. While in 35-39 age group there is a rate of $\% 13,9$, this rate declines to $\% 13,4$ in 30-34 age group. The frequency of accidents is declining at the age of 40 and older. The least work-accident-experienced age group is 60 and older age group with the rate of \%1. \%38,1 of the workers who are exposed to work accidents are under the age of 30 , and young population is exposed to work accidents the most. When work accidents that are resulted in death are examined, 18-24 age group is leading again as the young population. Besides, 60 and older age group has a low work accident rate of \%1 and since construction industry is in the dangerous and very dangerous workgroup, the number of workers in this industry might be effective in this rate due to a low number of workers. In 14 age group, there is nobody that is exposed to an accident.

In the distribution of work accidents according to types of accidents, Human fall is the most common accident type with \%32. The falling of materials is second in number with \%15,5. Fall type of accidents is the most common reason for the accident in Trabzon's construction industry. Apart from this, traffic accidents in construction sites have a considerable rate of $\% 7,7$. The collapse of the structure part type of accidents are the least accident types of all at the rate of $\% 1$.

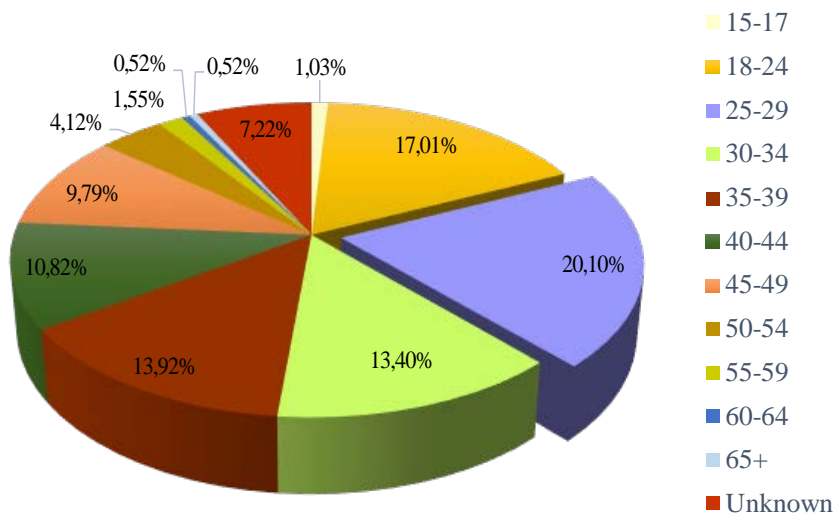

Fig. 6. Percent distribution of occupational accidents by age groups

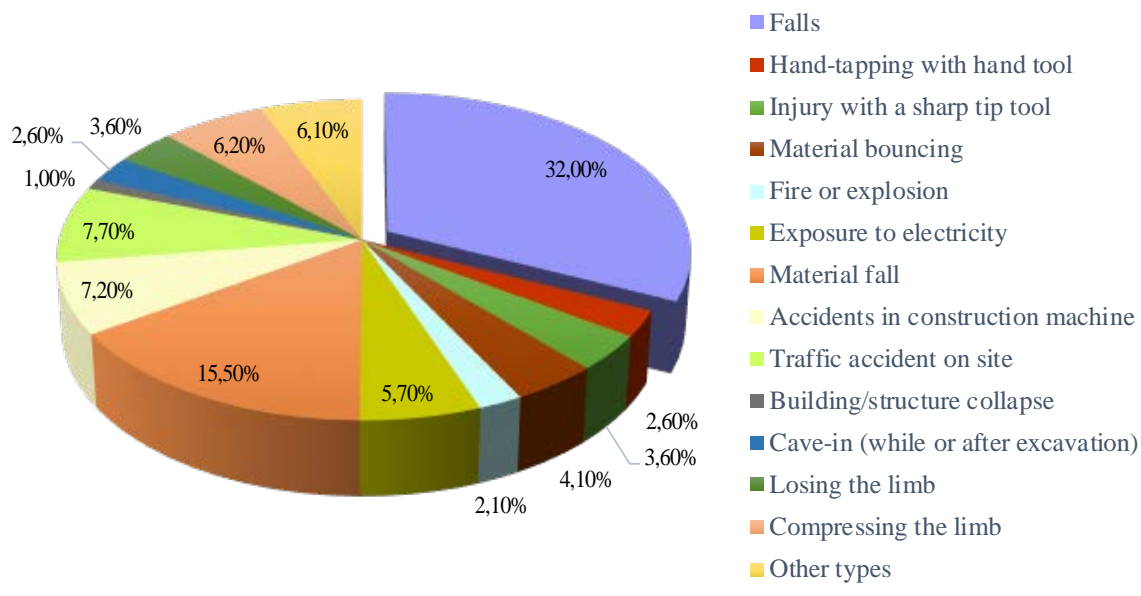

Fig. 7. Percent distribution of occupational accidents by accident type 
The size of the company where work accidents take place is again an important factor in examining the accidents. In order to define the size of the company, the number of the workers, in other words, insured workers in the workplace is used. In this study, size of the company is grouped below according to Social Security Institution's occupational accidents and professional diseases statistics, depending upon the number of the workers. The number of insured workers in the workplace:

$\begin{array}{lll}\cdot 1-3 & \bullet 4-9 & \cdot 10-20 \\ \cdot 21-49 & \bullet 50-99 & \cdot 100-199 \\ \cdot 200-249 & \bullet 250-499 & \cdot 500-1000 \\ \text { - Unknown } & & \end{array}$

The time that passes until the worker gets back to his job again because of a work accident is defined as the workday loss. In defining the workday loss, the classification of workday loss used by the Social Security Institution in statistics is used. According to this classification, workday losses:

$\begin{array}{lll}\cdot 1-3 & \cdot 4-6 & \cdot 7-13 \\ \cdot 14-20 & \cdot 21-30 & \cdot 31-90 \\ \cdot 91-183 & \bullet 184-364 & \cdot 365+ \\ \text { - Unknown } & & \end{array}$

Construction industry contains within lots of different construction site types. Every construction sites' operation, work order, environment, tools and types of equipment used, manufacturing, etc. is different. For this reason, it is crucial to evaluate the distribution of work accidents according to the types of construction sites. The distribution of occupational accidents in terms of the size of the company, the workday loss, and type of the construction site are given in Figs. 8-10, respectively. Type of the construction site in which accident takes place is classified below in accordance with the acquired data:

- Building

- Road construction

- Dam construction

- Channel and water supply works

Work accidents intensively take place in workplaces which have insured workers between 21-49 with \%19,1. \%15,5 is seen in workplaces which have insured workers between 10-20 and 5099. Work accidents are seen in workplaces which have insured workers between; 1-3 with a rate of $\% 13,9,100-199$ with a rate of $\% 12,9$, 4-9 with a rate of \%11,9. In other words, more frequent work accidents take place in workplaces that have 50 or fewer workers at a considerable rate of $\% 60$. Considering there are few big-sized companies in the construction industry and most of the companies incorporate 50 or fewer workers in Trabzon, \%60 seems normal.

While $\% 45,4$ of the work accidents causes 31 90 days of workday loss, $\% 43,3$ of them cause 4-30 days of workday loss. Mild accidents that cause 13 days of workday loss is not encountered.

Distribution of work accidents according to construction site types, building constructions are the most common construction sites work accidents take place. Dam constructions are the second most construction sites that accidents take place at a rate of \%19,6. The least accidents take place in demolition sites with \%1.

\section{Discussions}

This study is done in order to form an information repository to set to set an example for possible work accidents in the construction industry and prevention and to preclude accidents. 194 work accidents took place in construction industry between 2010-2011 in Trabzon, \%97 of these cases resulted in injuries, \%3 of them resulted in fatal accidents. 7656 work accidents took place in Turkey in same years in the construction industry and \%93 of the accidents are registered as injuries and $\% 7$ of them registered as fatal accidents. Therefore, most of the accidents have resulted in injuries. There is no data to be analyzed on sectoral basis in SSI statistical yearbook. The information related to the work accidents experienced in the construction sector in Turkey is not accessible from SSI statistical yearbook. Akboğa's [20] Ph.D. study has been seen as the most comprehensive work on the work accidents experienced in the construction sector in Turkey. For this reason, in the next comparisons, are benefited from this study. 


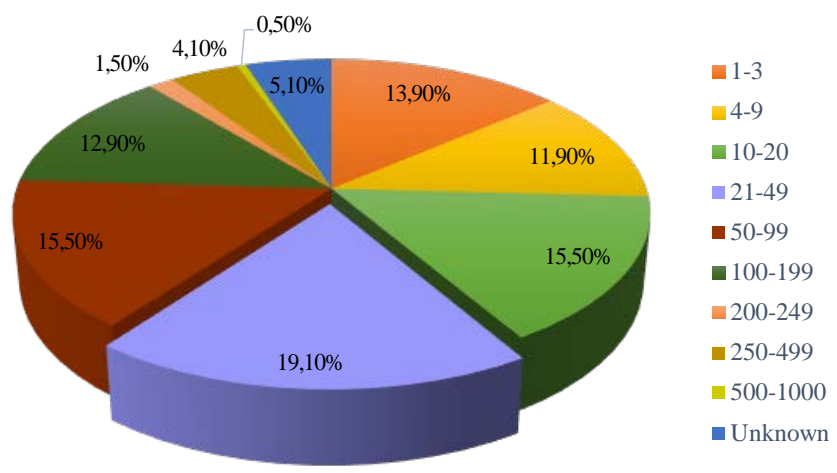

Fig. 8. Percent distribution of occupational accidents by the size of the company

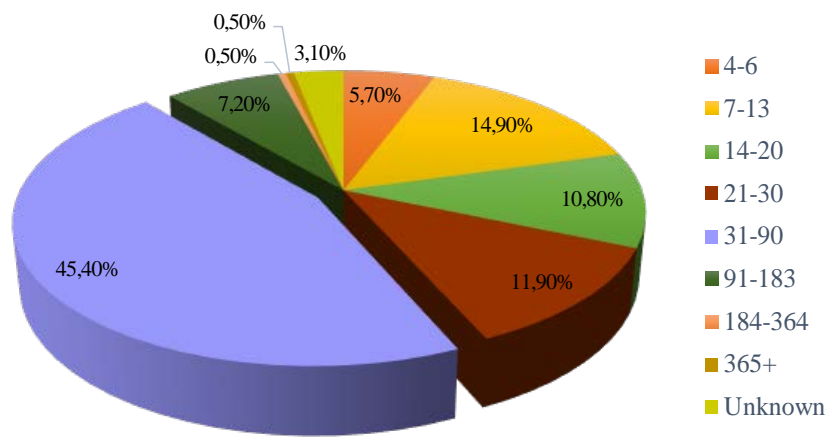

Fig. 9. Percent distribution of occupational accidents by the workday loss

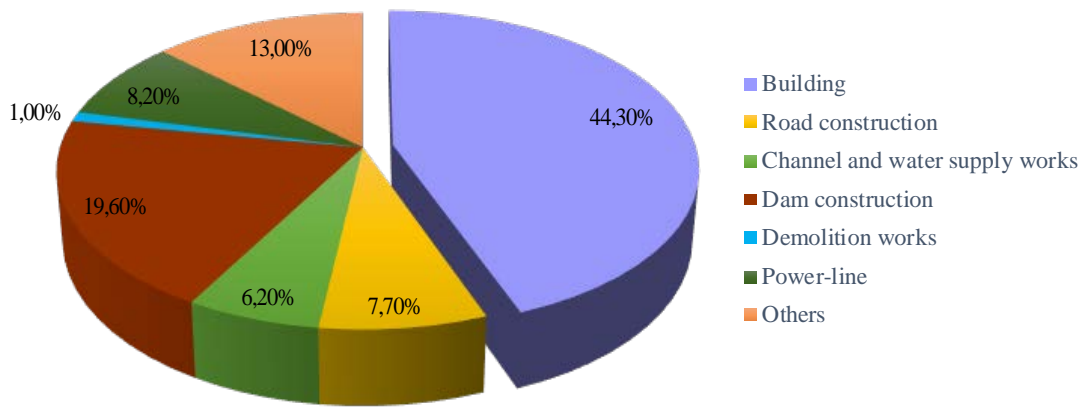

Fig. 10. Percent distribution of occupational accidents by type of the construction site

According to Turkish data, it has been found that most accidents with a frequency of $17.5 \%$ happen on Mondays and the number decreases gradually by the following days of the week. The frequency of accidents which occur on weekends is $21.8 \%$ in total. In this study, it was observed that most work accidents occur on Fridays and the frequency on weekends is $22.7 \%$ in total. At some workplaces in the construction industry, these rates are not at an ignorable level, even though Saturday afternoons and Sundays are not working hours. Increased fatigue in the last days of the week results in low concentration, which increases the incidence of work accidents. Article 63 of the Labor Law No. 4857 [31] contains provisions for 45 hours of weekly working hours and Article 4 of the Working 
Times Regulation for the Labor Law [32] rules that the daily working time cannot exceed 11 hours in any case. In the Overwork and Overtime Working Regulation for the Labor Law [33], which was issued to regulate the procedures and principles for overwork and overtime work apart from the weekly working time specified in Article 63 of the Labor Law No. 4857 [31] for reasons such as the general benefit of the country, increasing the quality of the job or the production, it is stated that the sum of the overtime work cannot exceed two hundred eightyone hours in a year. However, these times are much higher in the construction industry. In addition, the rest periods provided to workers are far below the current legal regulations. Due to the high working hours, workers' health deteriorates, job concentration decreases due to fatigue and the likelihood of accidents caused by lack of attention increases.

Upon examining the work accidents which occurred between 2010 and 2011 in the construction industry of Trabzon province in terms of working hours, one can see that most accidents with 43,3\% occurred in the morning hours. Similarly, the morning hours have been found to be the time period when most work accidents occur in Turkish data with $42.9 \%$ frequency. The fact that more work accidents in the morning hours have been experienced indicates that workers have some problems during the starting hours. These problems can arise from factors such as hardship in immediate adaptation and/or lack of attention. According to the Trabzon data, it is thought daily fatigue, loss of attention and boredom of work during the day are effective on the fact that work accidents are considerably high between 15:00 18:00 after the lunch, which is the second-time period when most work accidents have been observed. In the case of work accidents during midday hours, reasons such as low concentration after lunch, feeling weight and drowsiness in the body, and not being able to adapt immediately to work may have had influence.

When work accidents which occurred in Turkey were examined on a monthly basis, it was observed that more work accidents with a frequency of $29.7 \%$ occurred in winter months. The spring season is in the second place with a frequency of $27.7 \%$, passing the summer season with $21.5 \%$. According to this study, however, more job casualties with a frequency of $30.9 \%$ were experienced during summer months. Similarly, the spring season is in the second place. In the summer, work in the construction industry gains momentum whereas work motivation can decrease due to heat and excessive humidity and work accidents are more likely to occur. The province of Trabzon has a temperate climate, and there are no extreme temperature differences between seasons. Soft winter months, particularly, do not bring the work in the construction industry to a halt, and as a reflection of this situation, the seasonal data obtained have close values between each other.

The 18-29 age group constitutes the $37 \%$ of the workers who have had work accidents. Mostly, the young population is exposed to work accidents. Turkish data also similarly indicates that this age group is more frequently exposed to work accidents. The increase in age results in the decrease of work accidents. The experience of a worker increases as his age increases while the young who lack of work experience are overconfident. In addition to this, the fact that the workforce in the construction industry is made up of mostly young people results in the exposure of especially 18-29 age group to work accidents. The construction industry is generally in the Dangerous and Highly Dangerous classifications according to the Occupational Danger Classification Regarding Occupational Health and Safety and is among the prohibited jobs for children and young workers who are under the age of eighteen. For this reason, although no work accidents were belonging to the 14-year-old child worker group, who are prohibited from working in the sector, were found, $1 \%$ of the work accident records were registered in the 15-17 age group. Although it is a small proportion, it represents only the young workers who are exposed to a work accident and shows that there are too many young workers in the construction industry.

When the situations which resulted in accidents are considered, human fall is the leading accident 
type. This situation is followed by material drop. Similarly, fall accidents are the most common type of accidents in the Turkish construction industry. Human fall accidents can be sorted by falls from roofs and scaffolds, falls from elevator shafts and floor openings, falls from cranes, falls from stairs and work platforms, falls from slab openings, slipping and falling at the level crossings. Among these, the most common types are fallings from stairs and scaffolds [35]. The Ministry of Environment and Urbanization has issued the Communiqué on External Facade Scaffolds [36] as of 01.07.2015 in order to ensure the establishment of a safe working environment with external facade scaffolds and prevent accidents caused by external facade scaffolds. With this Communiqué, it is stipulated that the static calculations and detail drawings of the exterior work scaffoldings to be used in the building constructions should be made by the project developer and submitted to the administration together with other static projects during the construction permit phase.

$60 \%$ of the accidents at construction work have been seen in workplaces with less than 50 workers. Mortal accidents, on the other hand, have been frequently experienced at workplaces where there are 50-99 employees. No data on the number of employees expressing the size of the workplacespecific to the Turkish construction industry was found. For this reason, no comparison with Turkey could be done with respect to this data. The fact that companies in the Trabzon province construction industry are mostly small-scale enterprises has been effective in the incidence of more accidents. In addition, such reasons as the fact that these enterprises do not want to take precautions and measures required by OHS due to their weakness in economic terms, their workers' lack of training, lack of knowledge and experience on the job are thought to be influential in the increase of work accident ratios.

\section{Conclusions and suggestions}

While nearly $90 \%$ of accidents in industrialized countries are reported, this percentage is quite low in developing countries, reaching a small fraction of actual data. For these reasons, the ILO's final reports are only estimates. Again, there are a lot of informal workers in the construction sector, and the employees do not have any legal guarantees., Those who lack legitimate security, such as irregular migrants, are exposed to very low incomes and exploitation. These people are mostly employed in industries with significant health impacts such as mining, construction, heavy manufacturing, and agriculture. Informality should be avoided, and some deterrent sanctions should be applied to workplaces that employ children and young workers who are specifically prohibited from working in the sector. The data on experienced job accidents are important statements that need to be examined in order to be able to get ahead of the accidents and to find answers to the questions about why and how the accidents occurred. However, the data obtained should also contain all the information related to the accident. It is aimed that this study will be a comprehensive study in order to prevent possible accidents in the sector and to set an example for experienced job accidents. However, some difficulties have been encountered in reaching the data and the files that can allow multi-dimensional examination is limited to two years. The results of the findings determine that in the construction industry, job accidents in Trabzon show similarities with the job accidents in the construction industry that take place in Turkey in general.

Failure to comply with rest periods in the construction industry increases the risk of accidents and affects employee health negatively. Therefore, this situation causes the loss of labor and working days and indirectly brings material and moral damages to the economy of the country. It can be considered as a solution method as working in shifts system at the worksites where the continuity of work is very important. In addition, in order to prevent accidents during the morning hours, when work accidents are intensively observed, workers should be warned to ensure that they pay attention to what they are doing.

For the 18-29 age group, which is the leading age group in job accidents, more emphasis should 
be given on OHS studies, OHS training should be increased, and this age group should be tasked with OHS work. Furthermore, in OHS training, the most common type of work accident in the construction industry should be addressed more frequently, which is falling from heights, and the educational content should be supported with visuals and videos in an excess amount.

\section{References}

[1] Unsar, S., Necdet, S. General assessment of the occupational accidents that occurred in Turkey between the years 2000 and 2005. Safety Science 47(5) (2009) 614-619.

[2] Moore, J. T., Cigularov, K. P., Sampson, J. M., Rosecrance, J. C., Chen, P. Y. Construction workers' reasons for not reporting work-related injuries: an exploratory study. International Journal of Occupational Safety and Ergonomics (JOSE) 19(1) (2013) 97-105.

[3] U.S. Department of Labor, Bureau of Labor Statistics. National Census of Fatal Occupational Injuries in 2011. [Online]. Available: http://www.bls.gov/news.release/cfoi.nr0.htm. [Accessed:15- Feb-2017]

[4] U.S. Department of Labor, Bureau of Labor Statistics. Nonfatal Occupational Injuries and Illnesses Requiring Days Away from Work, 2015. [Online]. Available: http://www.bls.gov/news.release/osh2.nr0.htm. [Accessed:15- Feb-2017]

[5] Waehrer, G. M., Dong, X. S., Miller, T., Haile, E., Men, Y. Costs of occupational injuries in construction in the United States. Accident Analysis \& Prevention 39(6) (2007) 1258-1266.

[6] Probst, T. M., Brubaker, T. L., Barsotti, A. Organizational injury rate underreporting: the moderating effect of organizational safety climate. Journal of Applied Psychology 93(5) (2008) 11471154.

[7] Dong, X. S., Fujimoto, A., Ringen, K., Stafford, E., Platner, J. W., Gittleman, J. L., Wang, X. Injury underreporting among small establishments in the construction industry. American Journal of Industrial Medicine 54(5) (2011) 339-349.

[8] Higgs, P., Young, V. L., Seaton, M., Edwards, D., Feely, C. Upper extremity impairment in workers performing repetitive tasks. Plastic Reconstructive Surgery 90(4) (1992) 614-620.
[9] Probst, T. M., Estrada, A. X. Accident underreporting among employees: testing the moderating influence of psychological safety climate and supervisor enforcement of safety practices. Accident Analysis \& Prevention 42(5) (2010) 1438-1444.

[10] Silverstein, B. A., Stetson, D. S., Keyserling, W. M., Fine, L. J. Work-related musculoskeletal disorders: comparison of data sources for surveillance. American Journal of Industrial Medicine 31(5) (1997) 600-608.

[11] Weddle, M. G. Reporting occupational injuries: the first step. Journal of Safety Research 27(4) (1996) 217-223.

[12] ILO. World Social Security Report 2010-2011. [Online]. Available: http:/www.ilo.org/wcmsp5/groups/public/--dgreports/---dcomm/--publ/documents/publication/wcms_146566.pdf. [Accessed:01- Feb-2018]

[13] SSI (Social Security Institution). Work Accidents and Occupational Diseases Statistics. [Online]. Available:

http://www.sgk.gov.tr/wps/portal/sgk/tr/kurumsal/ istatistik/sgk_istatistik_yilliklari. [Accessed:01Feb-2018]

[14] Çilek, H. C. Research about the reasons and results of occupational accidents in construction sector. MSc Thesis, Akdeniz University, 2013.

[15] Yılmaz, N., Şenol, M. B. A fuzzy multi-criteria model and practice for occupational health and safety risk assessment process. Journal of the Faculty of Engineering and Architecture of Gazi University 32(1) (2017) 77-87 (in Turkish).

[16] Yılmaz, F., Çelebi, U. B. The importance of safety in construction sector: costs of occupational accidents in construction sites. Business and Economics Research Journal 6(2) (1996) 25-37.

[17] Ulubeyli, S., Kazaz, A., Er, B. Health and safety perception of workers in Turkey: a survey of construction sites. International Journal of Occupational Safety and Ergonomics (JOSE) 20(2) (2014) 323-338.

[18] Ceylan, H. Analysis of occupational accidents according to the sectors in Turkey. Gazi University Journal of Science 25(4) (2012) 909-918.

[19] Y1lmaz, F. Analysis of occupational accidents in construction sector in Turkey. Journal of Multidisciplinary Engineering Science and Technology (JMEST) 1(5) (2014) 421-428. 
[20] Akboğa, Ö. Modelling of construction accident severity using logistic regression. $\mathrm{PhD}$ Thesis, Ege University, 2014.

[21] Baradan, S., Akboğa, Ö., Çetinkaya, U., Usmen, M. Statistical analysis of heavy fall accidents in aegean region construction sector. 4. Occupational Health and Safety Symposium, 01-03 November 2013, Konya, Turkey (in Turkish).

[22] Akboğa, Ö., Baradan, S. Statistical analysis of occupational accidents of transmixer operators. 4. Occupational Health and Safety Symposium, 01-03 November 2013, Konya, Turkey (in Turkish).

[23] Hoła, B., Szóstak, M. An occupational profile of people injured in accidents at work in the Polish construction industry. Procedia Engineering 208 (2017) 43-51.

[24] Lee, W. H., Danny Tse, K. H., Ma, W. K. P. Applied technologies in minimizing accidents in construction industry. Procedia Environmental Sciences 36 (2016) 54-56.

[25] Salguero-Caparros, F., Suarez-Cebador M., RubioRomero J. C. Analysis of investigation reports on occupational accidents. Safety Science 72 (2015) 329-336.

[26] Chong, H. Y., Low, T. S. Accidents in Malaysian construction industry: statistical data and court cases. International Journal of Occupational Safety and Ergonomics (JOSE) 20 (2014) 503-513.

[27] Gürcanl1, G. E., Müngen, U. A new occupational safety risk analysis method in construction with fuzzy clusters. ITU Journal of Engineering 5(4) (2006) 83-94 (in Turkish).

[28] Gürcanl1, G. E. A risk analysis method for occupational safety in construction sites using fuzzy sets. PhD Thesis, Istanbul Technical University, 2006.

[29] Gürcanl1, G. E. Safety Work Through Design in Construction. Journal of Turkey Engineering News 469 (2011) 56-68 (in Turkish).

[30] Müngen, U. The main types of occupational accidents in our construction sector. Journal of Turkey Engineering News 469 (2011) 32-39 (in Turkish).

[31] Labour act of Turkey. Law No: 4857, Date of enactment: 22.05.2003, Published in the Official Gazette on 10 June 2003.

[32] The regulation of working time for labor law. Published in the Official Gazette on 06 April 2004.

[33] Overwork and overtime working regulation on labor law. Published in the Official Gazette on 06 April 2004.
[34] Workplace hazard classes regarding occupational health and safety. Published in the Official Gazette on 26 December 2012.

[35] Ardıç, B. Working height in the construction sector. 3. Occupational Health and Safety Symposium, 2123 October 2011, Çanakkale, Turkey (in Turkish).

[36] Communiqué on outer facade work scaffolding consisting of wood and prefabricated steel and aluminum alloy components. Published in the Official Gazette on 19 September 2014. 